\title{
KEY DRIVER OF KNOWLEDGE WORKER PRODUCTIVITY: THE ROLES OF PERSONAL KNOWLEDGE MANAGEMENT 2.0 AND DIGITAL COMPETENCE
}

\author{
Yudha Prakasa $^{1}$, Endang Siti Astuti ${ }^{2}$, Alifah Damayanti ${ }^{3}$ \\ Fakultas Ilmu Administrasi Universitas Brawijaya ${ }^{123}$ \\ Email: y.prakasa87@ub.ac.id ${ }^{1}$, endangsitiastuti@gmail.com² ${ }^{2}$, alifahdmynt@gmail.com³
}

\begin{abstract}
This research aims to know and explain whether there is a simultaneous influence between Personal Knowledge Management $2.0\left(\mathrm{X}_{1}\right)$ and Digital Competence $\left(\mathrm{X}_{2}\right)$ on Knowledge Worker Productivity $(\mathrm{Y})$, and the partial influence between Personal Knowledge Management $2.0\left(\mathrm{X}_{1}\right)$ on Knowledge Worker Productivity $(\mathrm{Y})$ and Digital Competence $\left(\mathrm{X}_{2}\right)$ on Knowledge Worker Productivity $(\mathrm{Y})$. This research is quantitative research and the research type is explanatory research. The number of samples in this study was 50 persons of employees in PT Alpha Teknologi Indonesia Malang. The sampling technique used is census sampling. Sources of data in this study were obtained from the primary data by spreading questionnaires to the respondents and secondary data derived from the documentation. The measurement scale used in this reseach is Likert scale. This research using descriptive statistics analysis and multiple linier regression analysis with a classic assumption test. Data on this research is processed using SPSS 23 for Windows.
\end{abstract}

Keywords: Personal Knowledge Management 2.0, Digital Competence, Knowledge Worker Productivity

\begin{abstract}
ABSTRAK
Penelitian ini bertujuan untuk mengetahui dan menjelaskan apakah ada pengaruh secara simultan antara Personal Knowledge Management $2.0\left(\mathrm{X}_{1}\right)$ dan Digital Competence $\left(\mathrm{X}_{2}\right)$ terhadap Knowledge Worker Productivity $(\mathrm{Y})$, serta pengaruh secara parsial antara Personal Knowledge Management $2.0\left(\mathrm{X}_{1}\right)$ terhadap Knowledge Worker Productivity $(\mathrm{Y})$ dan Digital Competence $\left(\mathrm{X}_{2}\right)$ terhadap Knowledge Worker Productivity (Y). Penelitian ini merupakan penelitian kuantitatif dengan jenis penelitian yaitu explanatory research (penelitian penjelasan). Jumlah sampel pada penelitian ini adalah 50 orang karyawan PT Alpha Teknologi Indonesia Kantor Malang. Teknik pengambilan sampel yang digunakan adalah census sampling (sampling jenuh). Sumber data dalam penelitian ini diperoleh dari data primer dengan menyebar kuesioner kepada responden dan data sekunder yang berasal dari dokumentasi. Skala pengukuran yang digunakan dalam penelitian ini adalah skala Likert. Teknik analisis data pada penelitian ini adalah analisis statistik deskriptif dan analisis regresi linier berganda dengan uji asumsi klasik. Data pada penelitian ini diolah menggunakan SPSS 23 for Windows.
\end{abstract}

Kata Kunci: Personal Knowledge Management 2.0, Digital Competence, Knowledge Worker Productivity 


\section{PENDAHULUAN}

Pengelolaan pengetahuan secara personal atau dengan kata lain Personal Knowledge Management merupakan bagian dari knowledge management yang menekankan pada kepentingan individu dalam proses penyerapan pengetahuan (Razmerita, et al, 2009). Personal Knowledge Management menjadi prasyarat penting bagi organisasi dalam upaya meningkatkan produktivitas anggotanya baik secara kualitas maupun kuantitas (Shujahat., et al, 2019). Personal Knowledge Management merupakan proses menciptakan, berbagi, dan menyimpan pengetahuan yang diperoleh individu untuk meningkatkan kemampuan individu dalam pemecahan masalah, pengambilan keputusan, kompetensi, dan inovasi (Tohiye dan Garfield, 2017). Pada proses penciptaan, berbagi, dan menyimpan pengetahuan, para knowledge worker tentunya mencari informasi dari berbagai sumber. Salah satu sumber informasi yang digunakan knowledge worker pada abad ke-21 yaitu World Wide Web.

Web 2.0 atau yang dikenal sebagai social web tools merupakan platform jaringan yang bersifat atraktif dimana pengguna dapat menulis, membaca, dan berkomunikasi satu sama lain (Mr. Sourish Dhar, 2016). Semakin berkembangnya social web tools memudahkan knowledge worker untuk mengakses serta menciptakan pengetahuan dan informasi sebagai upaya meningkatkan produktivitas dari knowledge worker. Penggabungan konsep personal knowledge management dengan social web tools disebut juga personal knowledge management 2.0 yaitu proses yang dilakukan oleh knowledge worker dalam pengelolaan, pembelajaran, dan penyerapan ilmu pengetahuan diakses melalui media elektronik yang bertujuan untuk meningkatkan produktivitas knowledge worker (Sondari, 2013). Perkembangan personal knowledge management 2.0 tidak dapat terlepas dari kompetensi dalam menggunakan teknologi untuk menyerap pengetahuan. Oleh karena itu, diperlukan kompetensi serta kemampuan dari knowledge worker dalam menggunakan teknologi agar proses penyerapan pengetahuan berjalan baik. Kemampuan knowledge worker dalam mengelola pengetahuan baik dalam menyerap, menciptakan, menyebarkan maupun menggunakan pengetahuan akan sangat berdampak pada knowledge worker productivity (Kianto., et al, 2019).
Perkembangan teknologi yang pesat mendorong knowledge worker perlu memiliki kemampuan serta kompetensi dalam memanfaatkan Information Communication Technology (ICT). Kemampuan dalam memanfaatkan Information Communication Technology (ICT) dapat berguna bagi knowledge worker untuk mendapatkan informasi yang diperlukan dalam menyelesaikan pekerjaan sehari-hari. Digital competency menjadi salah satu kompetensi yang wajib dimiliki knowledge worker sebagai kunci memenangkan di era digital. Digital competence merujuk kepada kemampuan dan keterampilan yang dimiliki seseorang saat menggunakan teknologi informasi dan komunikasi untuk menyelesaikan pekerjaaan serta membangun pengetahuan sebagai upaya terciptanya efisiensi dan efektivitas bagi organisasi (Ferrari, et al, 2012). Artinya, digital competence memiliki peran strategis dalam mendukung knowledge worker untuk dapat berbagi pengetahuan, berkolaborasi dan berkomunikasi, hingga menciptakan pengetahuan yang bermanfaat bagi peningkatan kinerja organisasi. Semakin tinggi digital competence, semakin tinggi pula knowledge worker productivity.

Lebih lanjut, kompetensi knowledge worker dalam menggunakan Information Communication Technology (ICT) sangat diperlukan pada era digital ini sebagai upaya peningkatan daya saing melalui peningkatan wawasan pengetahuan. Terlepas dari kebiasaan knowledge worker dalam menggunakan Information Communication Technology (ICT), ternyata masih terdapat berbagai tantangan yang dihadapi knowledge worker dalam menyerap pengetahuan dan informasi melalui sumber informasi elektronik Web 2.0. Berbagai tantangan mulai muncul ketika knowledge worker dihadapkan pada penyerapan pengetahuan dan informasi melalui sumber informasi elektronik Web 2.0. Tantangan yang dihadapi knowledge worker dalam penyerapan pengetahuan dan informasi dapat berdampak kepada terhambatnya efektivitas dan efisiensi pekerjaan dari knowledge worker (Farkas dan Török, 2011). Ketika efektivitas dan efisiensi pekerjaan knowledge worker terhambat, maka produktivitas dari knowledge worker akan mengalami penurunan.

Terdapat 3 (tiga) tantangan yang harus dihadapi oleh knowledge worker agar dapat mempertahankan dan meningkatkan 
produktivitasnya (Kianto., et al, 2019). Ketiga tantangan tersebut adalah (1) information overload, kondisi dimana knowledge worker memiliki terlalu banyak informasi dan mengalami kesulitan dalam memilih informasi sebagai pijakan dalam mengambil keputusan; (2) no information, kondisi dimana knowledge worker tidak memiliki informasi dan pengetahuan apapun yang dapat dijadikan sebagai alternatif pengetahuan yang akan diambil sebagai keputusan; (3) information cost, waktu dan sumber daya yang harus dialokasikan oleh knowledge worker dalam mencari informasi dan pengetahuan terkait dengan pekerjaannya. Ketiga tantangan tersebut akan menjadi hambatan bagi knowledge worker jika tidak diikuti dengan kemampuannya dalam mengelola pengetahuan, termasuk kemampuan digital yang berperan penting dalam upaya mendapatkan informasi dan pengetahuan yang diperlukan. Bahkan, dapat menurunkan efektivitas dan efisiensi kerja para knowledge worker yang akan berdampak pada kemampuan dalam berinovasi.

Perusahaan startup menjadi salah satu entitas bisnis yang mengharuskan mengatasi ketiga hambatan di atas. Laporan TechinAsia menyebutkan bahwa pada kuartal kedua tahun 2017, jumlah perusahaan startup di Indonesia sempat mengalami penurunan hingga $23 \%$ dibanding dengan tahun 2016 (Techinasia, 2017.). Pada periode tersebut, banyak dinamika yang terjadi pada startup mulai dari menutup layanan bisnis dan/atau mengubah model bisnisnya. Salah satu penyebab perusahaan startup gagal yaitu disebabkan oleh ketidaksiapan manajemen dalam mengelola sumber daya didalamnya (Salamzadeh, 2015). Pengelolaan sumber daya manusia tidak terlepas dari manajemen pengetahuan di dalam sebuah perusahaan.

PT Alpha Teknologi Indonesia sebagai perusahaan yang menggunakan Information Communication Technology (ICT) dalam aktivitas bisnisnya membutuhkan sumber daya manusia yang memiliki knowledge dan kemampuan yang unggul dalam bidang digital. Perusahaan Alpha Teknologi Indonesia bergerak dibidang teknologi, tentunya memerlukan karyawan yang memiliki digital competence. Perusahaan yang bergerak dibidang bisnis financial and technology ini menganggap bahwa dengan mengelola pengetahuan yang dimiliki karyawan sebagai upaya dalam meningkatkan produktivitas.
Produktivitas PT Alpha Teknologi Indonesia dari tahun ke tahun kian meningkat yang ditandai oleh meningkatnya penjualan dipasar dan kinerja akan knowledge worker.

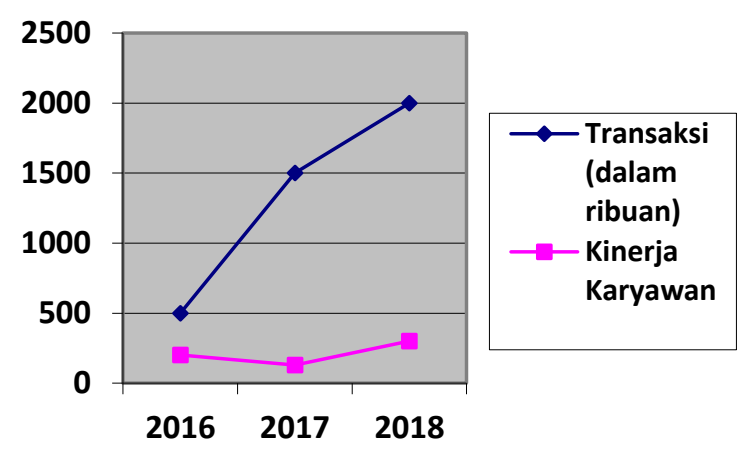

Gambar 1. Produktivitas PT. Alpha Teknologi Indonesia

(Sumber: PT. Alpha Teknologi Indonesia, 2019)

Grafik produktivitas PT. Alpha Teknologi Indonesia menunjukkan bahwa transaksi terus meningkat dari tahun ke tahun sejak 2016 hingga 2018, sedangkan pada grafik kinerja karyawan bersifat fluktuatif. Kinerja karyawan PT Alpha Teknologi Indonesia mengalami penurunan pada tahun 2017 dikarenakan salah satu leader mengundurkan diri. Pada saat itu, sebagian karyawan tidak ada yang pengelolaan dalam hal kinerja dan dapat disimpulkan bahwa rendahnya kedewasaan karyawan dalam hal produktivitas yang mengakibatkan penurunan kinerja karyawan. Pengelolaan dalam hal kinerja salah satunya berupa kompetensi yang dimiliki karyawan dan kemampuan terhadap pengetahuan yang dimiliki karyawan untuk menyelesaikan pekerjaan agar memiliki produktivitas yang baik.

Penelitian ini bertujuan untuk mengetahui pengaruh personal knowledge management 2.0 dan digital competence terhadap knowledge worker productivity. Personal knowledge management 2.0 yang diterapkan pada perusahaan ini dalam penggunaan aplikasi Web 2.0 antara lain presentation sharing dan wikis. Sedangkan, penerapan digital competence di perusahaan yang bergerak di bidang finance and technology ini yaitu kecakapan dalam mengoperasikan teknologi digital dalam menyelesaikan pekerjaan. Penelitin ini dilakukan di PT Alpha Teknologi Indonesia, salah satu start up yang bergerak di sektor fintech yang sedang berupaya untuk mengembangkan kriteria karyawan yang ingin 
terus belajar dan berkembang, mendorong agar terus berinovasi, tidak takut untuk melakukan kesalahan, dan menjadi seseorang yang berpikir kreatif. Hasil penelitian ini diharapkan dapat menjadi salah satu informasi bagi PT Alpha Teknologi Indonesia dalam mengambil kebijakan yang tepat. Berdasarkan pemaparan dan penjelasan permasalahan yang ada pada latar belakang ini, peneliti tertarik mengangkat judul penelitian "Key Driver of Knowledge Worker Productivity: The Roles of Personal Knowledge Management 2.0 and Digital Competence"

\section{KAJIAN PUSTAKA}

\section{Personal Knowledge Management 2.0}

Definisi personal knowledge management 2.0 merupakan gabungan konsep antara knowledge management, personal knowledge management dan Web 2.0 (Sondari, 2013). Lebih lanjut, Razmerita., et al (2009) mengungkapkan bahwa personal knowledge management merupakan bagian dari knowledge management yang menekankan pada kepentingan individu dalam proses penyerapan pengetahuan.

Pada konsep knowledge management, Polanyi dalam Tobing (2007:21) menjelaskan bahwa knowledge terdiri dari dua jenis yaitu tacit knowledge dan explicit knowledge. Tacit knowledge terdiri dari dua kata yaitu tacit yang berarti terbatinkan, intuisi, kepercayaan, nilai dan knowledge yang berarti pengetahuan. Explicit knowledge juga terdiri dari dua kata yaitu explicit yang berarti termodifikasi dalam dokumen dan knowledge yang berarti pengetahuan. Oleh karena itu, dapat disimpulkan bahwa tacit knowledge merupakan pengetahuan yang berasal dari batin, intuisi, kepercayaan dan nilai manusia yang sulit untuk ditransfer kepada orang lain. Sedangkan, explicit knowledge merupakan pengetahuan yang sudah terkodifikasi ke dalam bentuk dokumen atau bentuk berwujud lainnya sehingga pengetahuan tersebut mudah untuk dibagikan kepada orang lain.

Indikator dalam personal knowledge management 2.0 menggunakan instrumen yang dikembangkan oleh Sondari (2013) yang membagi proses personal knowledge management 2.0 menjadi 5 (lima), yaitu:

1) Connect (Socialization)

2) Share (Externalization)
3) Retrieve, Assess dan Organize (Combination)

4) Analyze, Understand dan Contextualize (Internalization)

5) Update dan Collaborating (ReSocialization)

\section{Digital Competence}

Pengertian digital competence dikemukakan oleh beberapa ahli. Ferrari., et al (2012) menyebutkan bahwa kompetensi digital merupakan seperangkat pengetahuan, keterampilan, sikap (termasuk kemampuan, strategi, nilai dan kesadaran) yang diperlukan saat menggunakan teknologi informasi dan komunikasi dan media digital untuk menyelesaikan pekerjaan, menyelesaikan masalah, menyampaikan dan mengelola informasi, berkolaborasi, membuat dan membagikan konten, dan membangun pengetahuan secara efektif, efisien, tepat, kritis, kreatif, mandiri, fleksibel, etis, reflektif untuk bekerja, sarana pembelajaran, serta bersosialisasi. Pendapat lain dikemukakan oleh Gallardo., et al. (2015) mengatakan bahwa digital competence merupakan kemampuan seseorang untuk mengoperasikan teknologi digital untuk menyelesaikan pekerjaan, hiburan, maupun pendidikan.

Lebih lanjut, Cartelli (2010) mendeskripsikan digital competence sebagai kemampuan seseorang dalam menggunakan Information Society Technology (IST) untuk menyelesaikan suatu pekerjaan yang didukung oleh ketrampilan dalam menggunakan ICT, seperti penggunaan komputer untuk mengambil, menilai, menyimpan, memproduksi, menyajikan dan bertukar informasi, dan untuk berkomunikasi dan berpartisipasi dalam jaringan kolaboratif melalui Internet. Definisi digital competence dari berbagai ahli terdapat beberapa persamaan didalamnya, dimana digital competence mencakup kemampuan seseorang untuk memiliki kompetensi dalam basis digital agar mempermudah pekerjaan. Penelitian ini menggunakan indikator Digital Competence yang dikembangkan oleh Cartelli (2010) bahwa digital competence terdiri dari 3 (tiga) indikator, yaitu:
1) Cognitive (Kognitif)
2) Affective (Afektif)
3) Relational (Relasi) 


\section{Knowledge Worker Productivity}

Konsep dan definisi knowledge worker productivity yang dikemukakan oleh para ahli mencakup dua hal yang krusial yaitu "doing the right things" dan "doing the things right". Menurut Drucker (1999), knowledge worker productivity mengacu kepada efisiensi seorang knowledge worker untuk mengoptimalkan pekerjaan yang berbasis pengetahuan agar dapat menghasilkan output berupa intelektual yang berbasis pengetahuan. Selanjutnya, Ramírez dan Nembhard (2004) berpendapat bahwa ketika seorang knowledge worker mengerjakan tugasnya secara produktif dan efektif maka produktivitas dari knowledge worker (knowledge worker productivity) akan memberikan keuntungan kepada perusahaan, mudah untuk mencapai tujuan, dan menciptakan daya saing. Berdasarkan berbagai pengertian yang dipaparkan dari para ahli, maka pengertian knowledge worker productivity dalam penelitian ini adalah kemampuan knowledge worker dalam menggunakan pengetahuan yang dimiliki untuk mengerjakan pekerjaan secara efektif dan efisien guna meningkatkan produktivitas.

Teori produktivitas mengacu pada perbandingan antara output dan input (Gordon, 1997). Sedangkan, terdapat beberapa tantangan dalam mengukur knowledge worker productivity mencakup tugas pekerjaan yang tidak menentu, tidak ada standar waktu dalam menghasilkan produksi, dan setiap knowledge worker memiliki jenis pekerjaan yang berbedabeda (Ramírez dan Nembhard, 2004). Artinya, teori knowledge worker productivity berkaitan dengan kemampuan knowledge worker dalam menyelesaikan pekerjaan sesuai dengan standar pekerjaan dan mencapai target yang ditentukan. Lebih lanjut, penelitian ini menggunakan teori yang dikemukakan oleh Gordon (1997). dimana indikator pengukuran knowledge worker productivity terdiri dari:

1) Quantity (Kuantitas)

2) Quality (Kualitas)

3) Timeliness (Ketepatan Waktu)

4) Multiple Priority

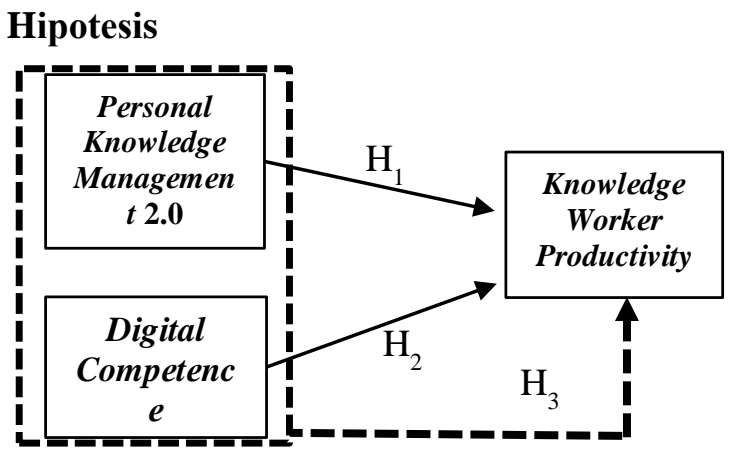

Gambar 2. Model Hipotesis

$\mathrm{H}_{1}$ : Terdapat pengaruh yang signifikan dari Personal Knowledge Management 2.0 $\left(\mathrm{X}_{1}\right)$ terhadap Knowledge Worker Productivity $\left(\mathrm{Y}_{1}\right)$

$\mathrm{H}_{2}$ : Terdapat pengaruh yang signifikan dari Digital Competence $\left(\mathrm{X}_{2}\right)$ terhadap Knowledge Worker Productivity $\left(\mathrm{Y}_{1}\right)$

$\mathrm{H}_{3}$ : Terdapat pengaruh yang signifikan dari Personal Knowledge Management 2.0 $\left(\mathrm{X}_{1}\right)$ dan Digital Competence $\left(\mathrm{X}_{2}\right)$ terhadap Knowledge Worker Productivity $\left(\mathrm{Y}_{1}\right)$

\section{METODE PENELITIAN}

Penelitian ini merupakan penelitian penjelasan (explanatory research) dengan pendekatan kuantitatif. Penelitian dilakukan di PT Alpha Teknologi Indonesia yang berlokasi di Malang Jawa Timur Indonesia. Pemilihan lokasi penelitian yang berada di Malang didukung dengan adanya divisi technology dimana aktivitas karyawannya harus memiliki kemampuan dalam mengelola pengetahuan. Populasi dalam penelitian ini adalah seluruh karyawan PT Alpha Teknologi Indonesia dengan total 50 orang. Teknik sampling menggunakan census sampling (sampling jenuh) sehingga melibatkan seluruh karyawan sebagai sampel. Pengumpulan data dilakukan dengan menyebar angket kepada responden sebagai sumber data primer serta dokumentasi sebagai data pendukung. Skala pengukuran menggunakan skala Likert dengan teknik analisis data statistik deskriptif dan analisis regresi linier berganda. Seluruh instrumen penelitian yang digunakan dalam penelitian ini telah melalui pengujian validitas dengan nilai $r$ hitung dari setiap item penelitian lebih besar dari $r$-tabel $(0,3)$ dan reliabilitas dengan nilai koefisien Alpha Cronbach $\geq 0,6$ dari setiap variabel penelitian yang digunakan. 


\section{HASIL DAN PEMBAHASAN \\ Profil Responden}

Responden penelitian ini didominasi oleh karyawan laki-laki (70\%) dengan usia $22-23$ tahun yakni sebanyak 19 orang (38\%) dan mayotitas memiliki latar belakang pendidikan Sarjana (33 orang; 66\%). Adapun masa kerja responden sebagian besar telah bekerja kurang dari 6 bulan (17 orang; 34\%) dan 1 hingga 2 tahun (14 orang; $28 \%$ ). Hal tersebut wajar mengingat lokasi penelitian merupakan perusahaan startup.

\section{Analisis Deskriptif}

a) Personal Knowledge Management $2.0\left(\mathrm{X}_{1}\right)$ Berdasarkan analisis deskriptif menunjukkan hasil grand mean dari variabel personal knowledge management $\left(\mathrm{X}_{1}\right)$ sebesar 4,06. Hal tersebut menunjukkan bahwa mayoritas responden menjawab setuju terhadap pernyataan yang telah diajukan pada item pernyataan variabel personal knowledge management $\left(\mathrm{X}_{1}\right)$. Jawaban responden pada item pernyataan $X_{1.1 .2}$ yaitu karyawan mengobrol (chatting) dengan rekan kerja melalui Web 2.0 merupakan item yang paling mendominasi atau paling mempengaruhi peningkatan knowledge worker productivity (Y) dengan hasil mean sebesar 4,32. Sedangkan, pada item pernyataan $\mathrm{X}_{1.2 .3}$ yaitu karyawan membagikan pengetahuan melalui tulisan (blogs) merupakan item yang memiliki nilai terkecil dari item lainnya dengan hasil mean sebesar 3,72. Hal ini menggambarkan karyawan PT Alpha Teknologi Indonesia kurang setuju dengan membagikan pengetahuan melalui tulisan (blogs).

Berdasarkan nilai rata-rata yang diperoleh dalam variabel personal knowledge management $\left(\mathrm{X}_{1}\right)$ sebesar 4,06 berada pada kategori baik dengan interval kelas 3,41-4,20, maka dapat disimpulkan bahwa personal knowledge management 2.0 yang dimiliki karyawan PT Alpha Teknologi Indonesia tergolong baik.

\section{b) Digital Competence $\left(\mathrm{X}_{2}\right)$}

Berdasarkan analisis deskriptif menunjukkan hasil grand mean dari variabel digital competence $\left(\mathrm{X}_{2}\right)$ sebesar 4,18. Hal tersebut menunjukkan bahwa mayoritas responden menjawab setuju terhadap pernyataan yang telah diajukan pada item pernyataan variabel digital competence $\left(\mathrm{X}_{2}\right)$. Jawaban responden pada item pernyataan $\mathrm{X}_{2.1 .1}$ yaitu karyawan mampu mengoperasikan dan memahami teknologi yang digunakan untuk menyelesaikan pekerjaan merupakan item yang paling mendominasi atau paling mempengaruhi peningkatan knowledge worker productivity (Y) dengan hasil mean sebesar 4,46. Sedangkan, pada item pernyataan $\mathrm{X}_{2.2 .4}$ yaitu karyawan menginternalisasi fenomena perkembangan teknologi merupakan item yang memiliki nilai terkecil dari item lainnya dengan hasil mean sebesar 3,88.

Berdasarkan nilai rata-rata yang diperoleh dalam variabel digital competence $\left(\mathrm{X}_{2}\right)$ sebesar 4,18 berada pada kategori baik dengan interval kelas 3,41 - 4,20, maka dapat disimpulkan bahwa digital competence yang dimiliki karyawan PT Alpha Teknologi Indonesia tergolong baik.

\section{c) Knowledge Worker Productivity (Y)}

Berdasarkan analisis deskriptif menunjukkan hasil grand mean dari variabel knowledge worker productivity (Y) sebesar 3,98. Hal tersebut menunjukkan bahwa mayoritas responden menjawab setuju terhadap pernyataan yang telah diajukan pada item pernyataan variabel knowledge worker productivity (Y). Jawaban responden pada item pernyataan $\mathrm{Y}_{1.1}$ yaitu karyawan dapat menyelesaikan semua pekerjaan yang menjadi tugas pokok merupakan item yang paling mendominasi dengan hasil mean sebesar 4,24. Sedangkan, pada item pernyataan $\mathrm{Y}_{2.1}$ dan $\mathrm{Y}_{3.2}$ yaitu karyawan mampu meminimalisir kesalahan dan tidak menunda pekerjaan yang telah diberikan merupakan item yang memiliki nilai terkecil dari item lainnya dengan hasil mean sebesar 3,82.

Berdasarkan nilai rata-rata yang diperoleh dalam variabel knowledge worker productivity (Y) sebesar 3,98 berada pada kategori baik dengan interval kelas 3,41-4,20, maka dapat disimpulkan bahwa knowledge worker productivity yang dimiliki karyawan PT Alpha Teknologi Indonesia tergolong baik.

\section{Analisis Inferensial}

Penelitian ini menggunakan nilai koefisien determinasi atau adjusted $\mathrm{R}^{2}$ untuk pengujian kelayakan model yang didapatkan dari hasil analisis regresi berganda. Tabel 1 menunjukkan hasil koefisien diterminasi dimana nilai Adjusted $R^{2}$ sebesar 0,453 menunjukkan proposisi pengaruh Personal Knowledge Management 2.0 $\left(\mathrm{X}_{1}\right)$ dan Digital Competence $\left(\mathrm{X}_{2}\right)$ terhadap Knowledge Worker Productivity 
(Y) sebesar 0,453. Artinya 45,3\% variabel Knowledge Worker Productivity (Y) dipengaruhi oleh variabel bebasnya yaitu Personal Knowledge Management $2.0\left(\mathrm{X}_{1}\right)$ dan Digital Competence $\left(\mathrm{X}_{2}\right)$. Sedangkan sisanya sebesar 54,7\% variabel Knowledge Worker Productivity (Y) akan dipengaruhi oleh variabel-variabel lainnya yang tidak dibahas dalam penelitian ini.

Tabel 1. Hasil Koefisien Determinasi

\begin{tabular}{|l|r|r|r|r|}
\hline Model & $\boldsymbol{R}$ & $\begin{array}{c}\boldsymbol{R} \\
\text { Square }\end{array}$ & $\begin{array}{c}\text { Adjusted } \\
\boldsymbol{R} \\
\text { Square }\end{array}$ & $\begin{array}{c}\text { Std. } \\
\text { Error of } \\
\text { the } \\
\text { Estimate }\end{array}$ \\
\hline 1 &, $689^{\mathrm{a}}$ &, 475 &, 453 & 3,882 \\
\hline
\end{tabular}

Sumber : Data Diolah, 2019

Selanjutnya, pengujian dilakukan secara parsial (uji t) sebagaimana ditunjukkan Tabel 2 yang menunjukkan bahwa hasil t test antara Personal Knowledge Management 2.0 (X1) terhadap Knowledge Worker Productivity (Y) menunjukkan $\mathrm{t}$-hitung $=2,845$ dan t-tabel $(\alpha=0,05 ; \mathrm{db}$ regresi $=2 ; \mathrm{db}$ residual $=47)$ adalah sebesar 2,012. Karena t-hitung $>\mathrm{t}$-tabel yaitu $2,845>2,012$ atau nilai sig $\mathrm{t}(0,007)<\alpha=0,05$ maka pengaruh Personal Knowledge Management 2.0 (X1) terhadap Knowledge Worker Productivity (Y) adalah signifikan. Hal ini berarti $\mathrm{H} 0$ ditolak dan $\mathrm{H} 1$ diterima sehingga dapat disimpulkan bahwa variabel terikat Knowledge Worker Productivity (Y) dipengaruhi secara signifikan oleh variabel bebas Personal Knowledge Management 2.0 (X1).

Lebih lanjut, hasil t test antara Digital Competence (X2) terhadap Knowledge Worker Productivity $(\mathrm{Y})$ menunjukkan thitung $=3,412$ dan ttabel $(\alpha=0,05 ; \quad d b \quad$ regresi $=2 ; \quad d b$ residual=47) adalah sebesar 2,012. Karena thitung $>$ ttabel yaitu 3,412>2,012 atau nilai sig t $(0,001)<\alpha=0,05$ maka pengaruh Digital Competence (X2) terhadap Knowledge Worker Productivity (Y) adalah signifikan. Hal ini berarti $\mathrm{H} 0$ ditolak dan $\mathrm{H} 1$ diterima sehingga dapat disimpulkan bahwa variabel terikat Knowledge Worker Productivity (Y) dipengaruhi secara signifikan oleh variabel bebas Digital Competence (X2).
Tabel 2 : Hasil Uji Parsial (Uji t)

\begin{tabular}{|l|l|l|l|l|}
\hline $\begin{array}{l}\text { Variabel } \\
\text { Terikat }\end{array}$ & $\begin{array}{l}\text { Variabel } \\
\text { Bebas }\end{array}$ & $\mathbf{t}_{\text {hitung }}$ & $\mathbf{t}_{\text {tabel }}$ & Sig. \\
\hline $\begin{array}{l}\text { Knowledge } \\
\begin{array}{l}\text { Worker } \\
\text { Productivity } \\
\text { (Y) }\end{array}\end{array}$ & $\begin{array}{l}\text { Personal } \\
\text { Knowledge } \\
\text { Management } \\
2.0\end{array}$ & 2,845 & 2,012 & 0,007 \\
\cline { 2 - 5 } & $\begin{array}{l}\text { Digital } \\
\text { Competence }\end{array}$ & 3,412 & 2,012 & 0,001 \\
\hline
\end{tabular}

Sumber : Data Diolah, 2019

Adapun penujian secara simultan (Uji F) sebagaimana Tabel 3 juga menunjukkan bahwa nilai $F_{\text {hitung }}$ sebesar 21,285 dan $F_{\text {tabel }}(\alpha=0,05 ; \mathrm{db}$ regresi $=2$; db residual $=47$ ) adalah sebesar 3,20. Karena $F_{\text {hitung }}>F_{\text {tabel }}$ yaitu 21,285 $>3,20$ atau nilai sig $F(0,000)<\alpha=0,05$ maka model analisis regresi adalah signifikan. Hal ini berarti $\mathrm{H}_{0}$ ditolak dan $\mathrm{H}_{1}$ diterima sehingga dapat disimpulkan bahwa variabel terikat Knowledge Worker Productivity (Y) dapat dipengaruhi oleh variabel bebas Personal Knowledge Management $2.0\left(\mathrm{X}_{1}\right)$ dan Digital Competence $\left(\mathrm{X}_{2}\right)$.

Tabel 3 : Hasil Uji Simultan (Uji F)

\begin{tabular}{|l|r|r|r|c|c|}
\hline \multicolumn{1}{|c|}{ Model } & $\begin{array}{c}\text { Sum of } \\
\text { Squares }\end{array}$ & $\mathbf{d f}$ & $\begin{array}{c}\text { Mean } \\
\text { Square }\end{array}$ & F & Sig. \\
\hline Regression & 641,437 & 2 & 320,719 & 21,285 &, $000^{\mathrm{b}}$ \\
\hline Residual & 708,183 & 47 & 15,068 & & \\
\hline Total & 1349,620 & 49 & & & \\
\hline
\end{tabular}

Sumber : Data Diolah, 2019

Personal Knowledge Management $2.0\left(\mathrm{X}_{1}\right)$ berpengaruh signifikan terhadap Knowledge Worker Productivity (Y)

Hasil uji statistik membuktikan bahwa Knowledge Worker Productivity (Y) berpengaruh signifikan terhadap Personal Knowledge Management $2.0\left(\mathrm{X}_{1}\right)$ atau dengan meningkatkan personal knowledge management 2.0 maka knowledge worker productivity akan mengalami peningkatan secara nyata. Hasil penelitian ini konsisten dan menguatkan penelitian Kianto., et al (2019). yang menyatakan bahwa knowledge creation dan knowledge utilization yang merupakain bagian dari konsep Personal Knowledge Management $2.0\left(\mathrm{X}_{1}\right)$ berpengaruh signifikan terhadap Knowledge Worker Productivity (Y). Penelitian ini juga sejalan dengan Shujahat., et al (2019) yang menemukan bahwa Personal Knowledge Management menjadi sumber utama dalam meningkatkan kualitas dan kuantitas dari produktivitas karyawan. 
Kemampuan karyawan dalam menyerap, menyeleksi dan mengelola pengetahuan memberikan pengaruh yang besar dalam peningkatan knowledge worker productivity sebagaimana dipersepsikan karyawan pada indikator Retrieve, Assess, Organize sebagai salah satu pembentuk Personal Knowledge Management. Kemampuan karyawan dalam melakukan komunikasi (chatting) dengan rekan kerja melalui Web 2.0 serta komitmen karyawan dalam menyelesaikan semua pekerjaan tugas pokok juga menjadi suatu fenomena yang memperkuat hipotesis ini diterima, termasuk profil responden yang didominasi karyawan berusia produktif (22 23 tahun) dengan latar belakang pendidikan sarjana. Artinya, kondisi tersebut yang mendorong karyawan memiliki kecenderungan untuk mengakses, mengevaluasi, mengelola ilmu pengetahuan dan informasi yang di dapat melalui Web 2.0. Hal tersebut di buktikan kesinambungan dengan indikator yang paling dominan adalah Retrieve, Assess, Organize.

\section{Digital Competence $\left(\mathbf{X}_{2}\right)$ berpengaruh signifikan terhadap Knowledge Worker Productivity (Y)}

Hasil uji statistik membuktikan bahwa

Digital Competence $\left(\mathrm{X}_{2}\right)$ berpengaruh signifikan terhadap Knowledge Worker Productivity (Y). Artinya, semakin meningkat digital competence maka knowledge worker productivity akan mengalami peningkatan secara nyata. Hasil penelitian ini sejalan dengan penelitian Cinque dan Bortoluzzi (2013) yang menyatakan bahwa Digital Competence $\left(\mathrm{X}_{2}\right)$ berpengaruh signifikan terhadap peningkatan ketrampilan secara berkelanjutan sehingga berdampak pada peningkatan kualitas maupun kuantitas output yang dihasilkan. Penelitian ini juga memperkuat pendapat Pirzada dan Khan (2013) yang mengungkapkan bahwa ketrampilan digital yang dimiliki oleh karyawan akan berdampak pada kemampuan karyawan dalam menyelesaikan pekerjaannya di era digital.

Kemampuan karyawan dalam mengoperasikan dan memahami teknologi yang digunakan untuk menyelesaikan pekerjaan serta keyakinan karyawan dapat menyelesaikan semua pekerjaan tugas pokok yang diberikan sebagaimana yang dipersepsikan tinggi oleh responden menjadi hal yang mampu memperkuat pengaruh digital competence terhadap knowledge worker productivity secara signifikan. Latar belakang karyawan yang memiliki usia yang relatif muda mempermudah dalam beradaptasi dengan dinamika perkembangan teknologi yang bermanfaat dalam penyelesaian pekerjaannya (kemampuan kognitif). Karakteristik pendidikan juga ikut menguatkan kematangan karyawan dalam mengoperasikan dan memahami teknologi.

Personal Knowledge Management $2.0\left(\mathrm{X}_{1}\right)$ dan Digital Competence $\left(\mathrm{X}_{2}\right)$ secara simultan berpengaruh signifikan terhadap Knowledge Worker Productivity (Y)

Hasil uji statistik membuktikan bahwa Personal Knowledge Management $2.0\left(\mathrm{X}_{1}\right)$ dan Digital Competence $\left(\mathrm{X}_{2}\right)$ secara bersama-sama terbukti berpengaruh signifikan terhadap Knowledge Worker Productivity (Y). Artinya, produktivitas kinerja karyawan akan semakin meningkat jika kemampuan pengelolaan pengetahuan dan kemampuan digital secara bersama-sama ikut ditingkatkan. Hasil membuktikan bahwa konsep Personal Knowledge Management dan Digital Competence dapat dipergunakan secara bersama-sama sebagai upaya meningkatkan Knowledge Worker Productivity, penelitian yang sebelumnya belum pernah dilakukan pengujian sebagaimana pengujian yang dilakukan hanya secara parsial Shujahat., et al (2019); Cinque dan Bortoluzzi (2013); dan Pirzada dan Khan (2013)

Karakteristik karyawan yang sebagian besar tidak hanya berusia muda dan berpendidikan tinggi, melainkan juga masa kerja yang kurang dari 6 bulan, cenderung memiliki motivasi tinggi untuk menunjukkan kinerja terbaiknya bagi perusahaan sehingga karyawan memiliki potensi dan peluang untuk terus mengembangkan karirnya di masa yang akan datang, salah satunya dengan meningkatkan personal knowledge management dan digital competence secara berkelanjutan sehingga mampu memberikan konstribusi terbaiknya bagi perusahaan.

\section{Keterbatasan Penelitian}

Penelitian ini masih menggunakan pendekatan kuantitatif dengan regresi berganda yang bersifat first-order sehingga belum secara utuh dan detail mampu menggambarkan pengaruh dari masing-masing indikator pembentuk variabel yang digunakan dalam penelitian ini. 


\section{KESIMPULAN DAN SARAN \\ Kesimpulan}

Penelitian ini menunjukkan bahwa Personal Knowledge Management 2.0 dan Digital Competence terbukti mampu menjadi key driver dalam upaya meningkatkan Knowledge Worker Productivity perusahaan. Berdasarkan hasil analisis deskriptif menunjukkan bahwa penerapan Personal Knowledge Management 2.0 pada PT. Alpha Teknologi Indonesia Malang telah dilakukan dengan sangat baik. Tingkat Digital Competence yang dimiliki karyawan PT Alpha Teknologi Indonesia Malang juga berada dalam kategori baik, begitu juga dengan Knowledge Worker Productivity yang berada dalam kategori yang baik. Seluruh hipotesis penelitian dapat diterima sehingga:

1. Personal Knowledge Management 2.0 $\left(\mathrm{X}_{1}\right)$ terbukti berpengaruh signifikan terhadap Knowledge Worker Productivity (Y)

2. Digital Competence $\left(\mathrm{X}_{2}\right)$ terbukti berpengaruh signifikan terhadap Knowledge Worker Productivity (Y)

3. Personal Knowledge Management 2.0 $\left(\mathrm{X}_{1}\right)$ dan Digital Competence $\left(\mathrm{X}_{2}\right)$ terbukti secara simultan berpengaruh signifikan terhadap Knowledge Worker Productivity (Y). Artinya,

\section{Saran}

1. Bagi perusahaan, perlu dipertimbangkan untuk mengembangkan kemampuan karyawan dalam optimalisasi knowledge sharing untuk memperkuat praktik knowledge management seperti membagikan pengetahuan dalam bentuk tulisan seperti contoh memo digital dalam lingkup perusahaan, dan mengolaborasikan pengetahuan karyawan dengan rekan kerja lain. Hal tersebut dapat mendukung peningkatan personal knowledge management 2.0 dan knowledge worker productivity yang lebih baik.

2. Bagi peneliti selanjutnya, dapat menambah variabel seperti pengelolaan pengetahuan berbasis Web 3.0 maupun Web 4.0, digital literacy, knowledge sharing, innovation capability, learning environment, absorptive capacity yang dapat mempengaruhi Knowledge Worker Productivity dengan pendekatan metedologi dan/atau karakteristik objek penelitian yang berbeda

\section{DAFTAR PUSTAKA}

Cartelli, A. (2010). Frameworks for Digital Competence Assessment: Proposals, Instruments and Evaluation. Proceedings of the 2010 InSITE Conference, (December), 561-574. https://doi.org/10.28945/1274

Cinque, M., \& Bortoluzzi, M. (2013). Navigating complex challenges: Digital competence and personal knowledge management in university education to foster skills for lifelong learning. International Journal of Technology Enhanced Learning, 5(3-4), 284-298. https://doi.org/10.1504/IJTEL.2013.0594 96

Drucker, P. F. (1999). Knowledge-Worker Productivity: The Biggest Challenge.

Farkas, M. F., \& Török, L. G. (2011). Knowledge workers, competencies, virtuality and management. Polish Journal of Management Studies, 4(1), 1238.

Ferrari, A., Punie, Y., \& Redecker, C. (2012). Understanding Digital Competence in the 21st Century: 79-92. Retrieved from http://link.springer.com/10.1007/978-3642-33263-0_7

Gallardo-Echenique, Eliana, Oliveira, Janaina, Marqués Molías, Luis, dan Esteve, Francesc. (2015). Digital Competence in the Knowledge Society. MERLOT Journal of Online Learning and Teaching (JOLT), 11(1), 1-16.

Gordon, G. . (1997). The last word on productivity and telecommuting. Retrieved December 9, 2020, from http://www.gilgordon.com/downloads/pr oductivity.txt

Kianto, A., Shujahat, M., Hussain, S., Nawaz, F., \& Ali, M. (2019). The impact of knowledge management on knowledge worker productivity. Baltic Journal of Management, 14(2), 178-197. https://doi.org/10.1108/BJM-12-20170404

Mr. Sourish Dhar, S. B. N. K. (2016). Web 1.0 
to Web 3.0 - Evolution of the Web and its Various Challenges Keshab. Imperial Journal of Interdisciplinary Research, 2(4), 705-710.

Pirzada, K., \& Khan, F. N. (2013). Measuring Relationship between Digital Skills and Employability. European Journal of Business and Management, 5(24), 124133.

Ramírez, Y. W., \& Nembhard, D. A. (2004). Measuring knowledge worker productivity: A taxonomy. Journal of Intellectual Capital, 5(4), 602-628. https://doi.org/10.1108/14691930410567 040

Razmerita, L., Sudzina, F., \& Kirchner, K. (2009). Personal knowledge management: The role of Web 2.0 tools for managing knowledge at individual and organisational levels. Online Information Review, 33(6), 1021-1039. https://doi.org/10.1108/14684520911010 981

Salamzadeh, A. (2015). Startup CompaniesLife Cycle and Challenges Startup Companies: Life Cycle and Challenges Aidin Salamzadeh (Corresponding author ) Faculty of Entrepreneurship, University of Tehran, 16th Street, North Kargar Hiroko Kawamorita Kesim Faculty of Enginee. 4th International Conference on Employment, Education and Entrepreneurship (EEE), (August). https://doi.org/10.13140/RG.2.1.3624.81 67

Shujahat, M., Razzaq, S., Wang, M., \& Durst, S. (2019). Personal knowledge management and knowledge worker productivity in the healthcare sector. Proceedings of the European Conference on Knowledge Management, ECKM, 2, 933-940.

https://doi.org/10.34190/KM.19.095

Sondari, M. C. (2013). Personal Knowledge Management 2.0. International Journal of Social Science and Humanity, 3(4), 426428.

https://doi.org/10.7763/ijssh.2013.v3.275

Techinasia. (2017). Laporan Kondisi Startup Indonesia Kuartal Kedua 2017. Retrieved December 9, 2020, from https://id.techinasia.com/laporan-kondisistartup-indonesia-q2-2017

Tobing, Paul L. (2007). Knowledge Management: Konsep, Arsitektur dan Implementasi. Yogyakarta: Graha Ilmu.

Tohiye K., G. M. (2017). Personal Knowledge Management: Systematic Review and Future Direction'. World Academy of Science, Engineering and Technology. 11(1), 53-58. 